\title{
Condições agrometeorológicas para perfilhamento máximo da cultura de cana-de-açúcar em dois ambientes distintos de produção
}

\author{
Renã Moreira Araújo ${ }^{1}$, Ricardo Augusto de Oliveira ${ }^{2(*)}$, Santiago Vianna Cuadra ${ }^{3}$, Ivan Rodrigues de Almeida ${ }^{4}$, Heroldo Weber ${ }^{5}$ \\ ${ }^{1}$ Doutorando do Programa de Produção Vegetal, Universidade Federal do Paraná, Curitiba, Paraná, rena543@gmail.com \\ ${ }^{2}$ Professor Adjunto do Programa de Produção Vegetal, Universidade Federal do Paraná, Curitiba, Paraná, rico@ufpr.br \\ ${ }^{3}$ Pesquisador, Embrapa Clima Temperado, Pelotas, Rio Grande do Sul, santiago.cuadra@embrapa.br \\ ${ }^{4}$ Pesquisador, Embrapa Clima Temperado, Pelotas, Rio Grande do Sul, ivan.almeida@embrapa.br \\ ${ }^{5}$ Engenheiro Agronômo, Universidade Federal do Paraná, Curitiba, Paraná, heroldo@ufpr.br \\ ${ }^{(*)}$ Autor para correspondência
}

\section{INFORMAÇÕES}

História do artigo:

Recebido em 16 de Junho de 2017

Aceito em 10 de agosto de 2017

Termos para indexação:

Saccharum officinarum $L$.

RB867515

temperatura

radiação solar

\section{RESUMO}

Estudos que buscam compreender o comportamento dos genótipos de cana-de-açúcar em diferentes ambientes de produção possuem elevada importância, pois são informações úteis em diversas áreas de estudo. O objetivo deste trabalho foi analisar as condições de temperatura e radiação solar que a variedade comercial RB867515 necessitou para atingir o máximo número de perfilhos em dois ambientes distintos de produção, localizados ao sul do Estado do Rio Grande do Sul e na região noroeste do Estado do Paraná. Foram utilizados dados de perfilhos de quatro experimentos realizados entre outubro de 2014 à abril de 2017. Utilizou-se 1,4 m de espaçamento entrelinhas no experimento 1 (RS) enquanto que nos outros experimentos (2, 3 e 4 - PR) foram de 1,5 m. Todos os plantios foram em toletes, com $10 \mathrm{~cm}$ de profundidade e distribuição média de 18 gemas por metro linear. $\mathrm{Na}$ contagem de perfilhos utilizou-se o delineamento inteiramente casualizado, com quatro repetições em cada amostragem, ao longo dos dias após o plantio (DAP). Os dados meteorológicos usados foram temperatura média e radiação solar global. Os ambientes apresentaram diferentes tempos (DAP) para atingir o máximo número de perfilhos por metro linear; Os ambientes com maior incidência de radiação solar globlal e temperaturas mais elevadas na fase incial do ciclo atingiram valores mais elevados de máximo perfilhos; Os plantios de outubro atingiram valores mais altos de número máximo de perfilhos; o número máximo de perfilhos não indicou númeá ro elevado de colmos industrializáveis.

(C) 2017 SBAgro. Todos os direitos reservados.

\section{Introdução}

O Estado do Rio Grande do Sul apresenta-se como um potencial produtor da cultura da cana-de-açúcar, com produtividades na ordem de 100 ton ha-1 (VERISSIMO et al., 2012). Este valor representa produtividade de 38,9\% acima da atual média nacional que é de 72,6 ton ha-1 (CO$\mathrm{NAB}, 2017)$. Estudos relatam que o alto fotoperíodo e a radiação solar sob o estado durante o verão e ocorrência de precipitação bem distribuída ao longo do ano favorecem o 
crescimento das variedades de cana-de-açúcar (ALMEIDA et al., 2008). No entanto, à nível nacional, no ano de 2015, o estado foi o $17^{\circ}$ no ranking de produção da cultura de cana-de-açúcar, com 0,26 e 0,60\% da produção e área plantada, respectivamente (SEPLAG-EMATER, 2015).

Em contrapartida, o Estado do Paraná possuiu uma área cultivada de 617,7 mil ha da cultura de cana-de-açúcar na safra 2016/2017, com produtividade 68,35 ton ha-1, valor abaixo da média nacional, de 72,6 ton ha $^{-1}$ nesta safra (CONAB, 2017).

Apesar das distintas produtividades relatas acima, são poucos os experimentos que inter-relacionam fatores como clima, solo e variedades com a fenologia da canade-açúcar (SUGUITANI, 2006). Uma vez que são escassas as informações a respeito das exigências climáticas da cultura, estudos como o presente que buscam compreender o comportamento dos genótipos em diferentes ambientes de produção possuem elevada importância, pois estas informações são úteis em diversas áreas de estudo, como a do melhoramento genético, modelagem agroclie mática, manejo da cultura e estimativa de produtividade, por exemplo.

Neste sentido, este trabalho tem por objetivo analisar as condições de temperatura e radiação solar para a expressão do máximo perfilhamento da variedade comercial RB867515, em dois ambientes distintos de produção.

\section{Material e métodos}

Foram utilizados dados de quatro experimentos com a cultura de cana-de-açúcar realizados entre outubro de 2014 à abril de 2017. O primeiro deles, o experimento 1 , ocorreu na Sede da Embrapa Clima Temperado, (3140'24"S, 52²6'17"O e 50 m), situada no munícipio de Pelotas-RS. Os demais, ou seja, experimentos 2, 3 e 4 foram realizados na Estação Experimental do Programa de Melhoramento Genético da Cana-de-Açúcar (PMGCA), pertencente à Universidade Federal do Paraná, no município de Paranavaí-PR (2241.7 “58”” S, 52²8’ 03” O, 470 m). A localização e data de plantio de cada experimento segue detalhados na Tabela 1.

O espaçamento entrelinhas do experimento 1 foi de 1,4 $m$ enquanto que dos outros experimentos (2, 3 e 4) foram de 1,5 m. Em todos os experimentos foram utilizados a va- riedade comercial RB867515, plantada em toletes, com 10 $\mathrm{cm}$ de profundidade e distribuição média de 18 gemas por metro linear.

O solo da área experimental 1 foi classificado como ARGISSOLO VERMELHO-AMARELO Eutrófico Abrúptico A Moderado, com horizonte A preservado (PVAe2). A calagem e adubação foram determinadas através de análise química do solo. A calagem foi realizada com calcário dolomítico com dosagem de $945,27 \mathrm{~kg} \mathrm{ha}^{-1}$. A adubação usada foi o formulado 36-0-12 (N, P, K), aplicado em duas doses, a primeira de $150 \mathrm{~kg} \mathrm{ha}^{-1}$ dia 22 de dezembro de 2014, e a segunda de $100 \mathrm{~kg} \mathrm{ha}^{-1}$, aplicada no mês de janeiro de 2015 . Já o solo da área experimental dos experimentos 3 ,2 e 4 foi classificado como LATOSSOLO VERMELHO Distrófico, sendo o de maior representatividade regional, com ocorrência superior a 50\%. São solos muito profundos, constituídos por material mineral, de origem do Arenito Caiuá, apresentando horizonte B latossólico. Possuem saturação por bases baixa (V \&lt; 50\%) na maior parte dos primeiros $100 \mathrm{~cm}$ do horizonte B (inclusive BA) (EMBRAPA, 2006). Foi realizada calagem no preparo do solo, com aplicação de 1,8 ton ha-1 de calcário dolomitíco, e adubação de base no sulco de plantio com formulado 10-20-20 (N, P, K).

No levantamento do número de perfilhos por metro linear, utilizou-se o delineamento inteiramente casualizado (DIC), com quatro repetições em cada amostragem. As contagens dos números de perfilhos foram realizadas em cinco metros lineares, marcados na primeira contagem de cada experimento e acompanhados nas datas subsequentes. As datas após o plantio (DAP) das amostragens do experimento 1 foram aos: $88,101,119,133,151,165,179,193$, 213, 232, 261 e 276 DAP; do experimento 2 foram: 33, 49, $65,82,90,105,119,147,174,187,230,272,302$ e 324 DAP; do experimento 3: 52, 60, 72, 79, 87, 82, 109, 135, 150, 177 e 207 DAP; e do experimento 4: 29, 55, 70, 97, 127, e 149. Portanto, tem-se para o experimento 1, 2, 3 e 4, respectivamente, 12, 14, 11 e 6 datas de amostragens. Em seguida, realizou-se regressão para definir a época do ponto máximo perfilhamento de cada experimento e seguiu-se para a análise agrometeorológica. Vale ressaltar que os experimentos 2, 3 e 4, até a data do presente trabalho não havia sido colhidos.

$\mathrm{Na}$ análise agrometeorológica, utilizou-se no experi-

Tabela 1. Detalhes da localização e data de plantio dos quatro experimentos realizados.

\begin{tabular}{ccccc}
\hline Experimento & Localização & Lat $\left(^{\circ}\right)$ & Lon $\left(^{\circ}\right)$ & Data de plantio \\
\hline 01 & $\begin{array}{c}\text { Rio Grande } \\
\text { do Sul }\end{array}$ & $31^{\circ} 40^{\prime} 24^{\prime \prime} \mathrm{S}$ & $52^{\circ} 26^{\prime} 17^{\prime \prime} \mathrm{O}$ & $13 / 10 / 2014$ \\
02 & Paraná & $22^{\circ} 58^{\prime} 41,7^{\prime \prime} \mathrm{S}$ & $52^{\circ} 28^{\prime} 03^{\prime \prime} \mathrm{O}$ & $20 / 04 / 2016$ \\
03 & Paraná & $22^{\circ} 58^{\prime} 41,7^{\prime \prime} \mathrm{S}$ & $52^{\circ} 28^{\prime} 03^{\prime \prime} \mathrm{O}$ & $25 / 07 / 2016$ \\
04 & Paraná & $22^{\circ} 58^{\prime} 41,7^{\prime \prime} \mathrm{S}$ & $52^{\circ} 28^{\prime} 03^{\prime \prime} \mathrm{O}$ & $13 / 10 / 2016$ \\
\hline
\end{tabular}




\section{Experimento_01}

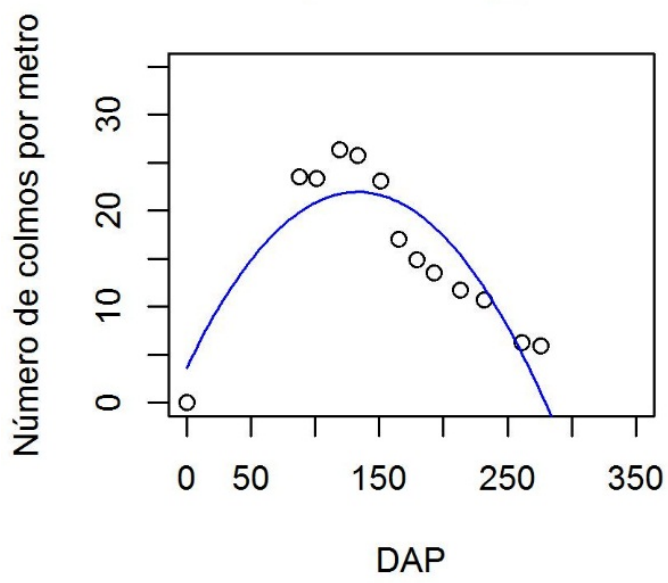

Experimento_03

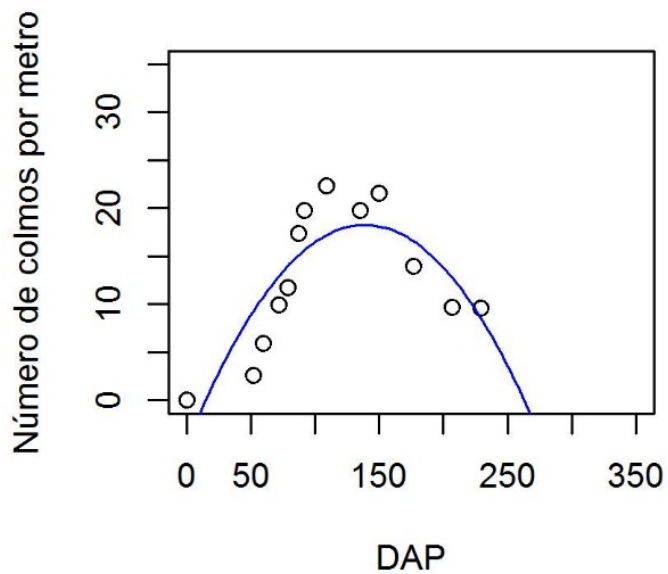

Experimento_02

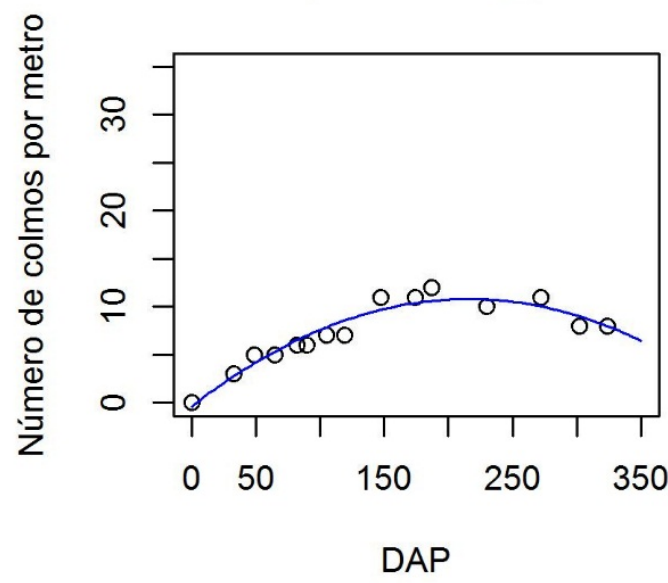

Experimento_04

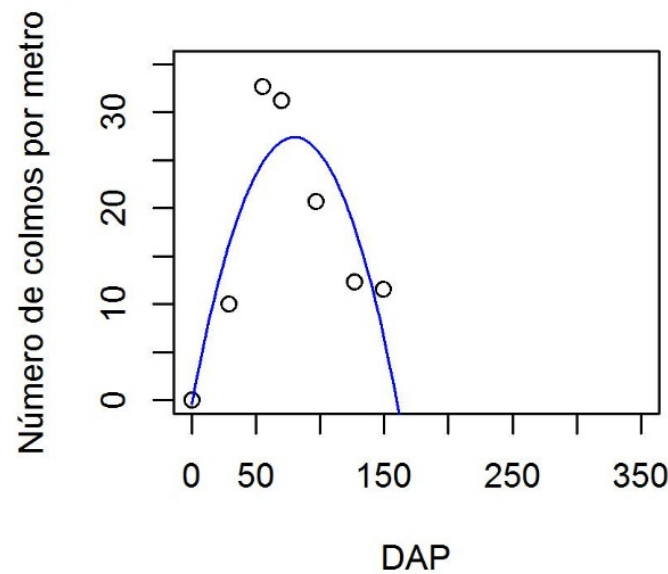

Figura 1. Perfilhamento da variedade RB867515 nos quatro experimentos realizados nos dois ambientes de produção, entre outubro de 2014 e março de 2017. **A curva de regressão foi significativa à 5\% de probabilidade de acordo com o teste F da análise de variância da regressão.

mento 1 os dados de temperaturas médias $\left({ }^{\circ} \mathrm{C}\right)$ e radiação solar global ( $\left.\mathrm{W} \mathrm{m}^{-2}\right)$, obtidos a partir da estação meteorológica automática, modelo Davis Vantage PRO2 situada a $1100 \mathrm{~m}$ do talhão experimental. Para os demais experimentos, foram utilizados os dados dos mesmos elementos meteorológicos, provenientes de uma estação meteorológica automática idêntica a supracitada, situada à $50 \mathrm{~m}$ do talhão experimental.

\section{Resultados e discussão}

Na Figura 1 tem-se o número de perfilhos por metro linear ao longo dos DAP, para cada experimento realizado. Observou-se que o experimento 4, ambiente localizado no noroeste do Estado do Paraná, apresentou o mais elevado máximo de perfilhos, atingindo $32,7 \mathrm{~m}^{-1}$ aos 55 DAP (Figura 1). 0 experimento 1, localizado no sul do Estado do Rio Grande do Sul ficou em segundo colocado em máximo número de perfilhos, atingindo $26,41 \mathrm{~m}^{-1}$ aos $119 \mathrm{DAP}$, ou seja, praticamente o dobro do tempo que o experimento 4 levou para atingir o máximo perfilhamento e 19,2\% a menos perfilhos por metro linear. Vale ressaltar que os experimentos 1 e 4 foram implantados no mesmo dia do ano.

Os experimentos 3 e 2 alcançaram 22,25 e 12,4 perfilhos $\mathrm{m}^{-1}$, aos 109 e 187 DAP, respectivamente, representando 31,95 e $62,07 \%$ perfilhamento máximo abaixo do atingindo no experimento 4. Nota-se que aos 100 DAP, apenas o experimento 2 não possuía mais de 10 perfilhos $\mathrm{m}^{-1}$. Desta forma, em ordem decrescente de máximo perfilhamento $\mathrm{m}^{-1}$ ficamos: experimento 4, 1, 3 e 2. Em relação aos DAP para atingir o ponto máximo de perfilhos, o experimento mais rápido foi o 4 (55 DAP), seguido do experimento 3 (109 DAP) , 1 (119 DAP) e 2 (187 DAP). Temos portanto que, os plantios realizados nos meses de outubro (experimentos 1 e 4) foram os que atingiram valores mais elevados de máximo perfilhos enquanto que o plantio realizado em abril (experimento 2) atingiu o menor valor máximo de perfilhos. 
Suguitani e Matsuoka (2001) afirmam que após o ponto máximo de perfilhos, há um decaimento do mesmo, diminuindo até atingir a estabilidade, que se mantém, em geral, constante até o fim do ciclo. 0 experimento 2, plantado em abril de 2016 no noroeste do PR, foi o que menos apresentou diminuição de perfilhos ao longo do ciclo e, manteve uma relativa estabilidade ao longo do ciclo, como pode ser observado na Figura 1. Nota-se que os demais experimentos, após atingir o ponto de máximo perfilhamento, sofrem uma diminuição abrupta na quantidade do mesmo, atingindo uma estabilidade. A não estabilidade pode fruto da competição intraespecífica da planta. A redução de mais da metade do número máximo de perfilhos corrobora estudos de Oliveira et al. (2004), que observou este efeito em outras variedades no Estado do Paraná.

Ao fim do ciclo, a quantidade de perfilhos por metro linear na verdade representa a quantidade de colmos industrializáveis. No campo, o experimento 1 possuía 10,7 perfilhos $\mathrm{m}^{-1}$, aos $232 \mathrm{DAP}$, enquanto que o experimento 2 possuía 10,45 aos 230 DAP e o experimento 3 possuía 9,6 aos 229 DAP. Este fato revela que atingir elevado número máximo de perfilhamento, como ocorreu com o experimento 1, não indica necessariamente que refletirá em elevado colmos industrializáveis ao decorrer do ciclo. Isto fica fortemente evidenciado ao compararmos o fim do ciclo entre os experimentos 1 e 2. Note que aos 276 DAP o experimento 1 possuía apenas 5,85 perfilhos $\mathrm{m}^{-1}$, enquanto que o experimento 2 mostrou 11,4 aos 272 DAP. Esse padrão de estabilização da população final de perfilhos é uma característica típica da cultura também foi previamente reportado por outros autores em tipos de ensaios experimentais (SUGUITANI; MATSUOKA, 2001; OLIVEIRA et al., 2004).

Essas diferenças no número máximo e redução de perfilhos ao longo do ciclo pode ser reflexo das condições edafoclimáticas, como a radiação solar, temperatura ambiente e do solo, umidade do solo, insolação dentre outras.

\section{Experimento_01}

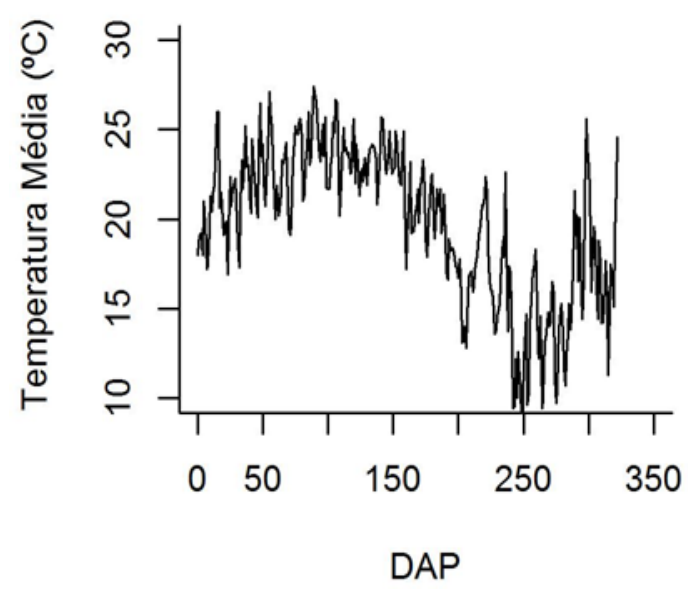

\section{Experimento_03}

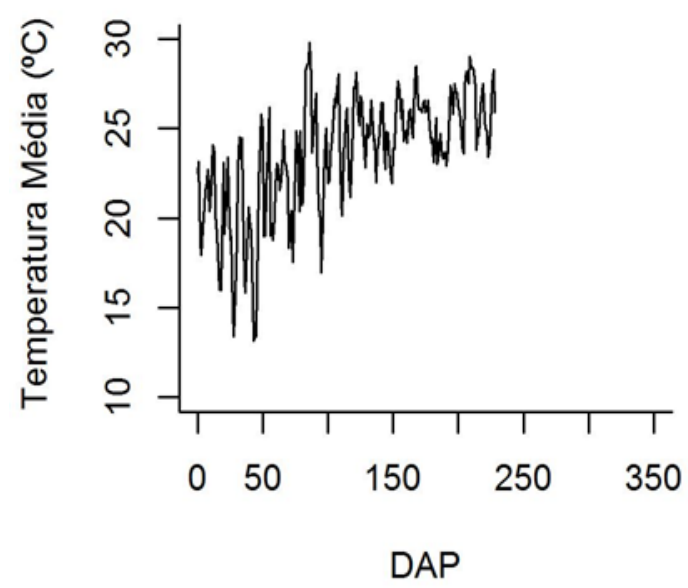

\section{Experimento_02}

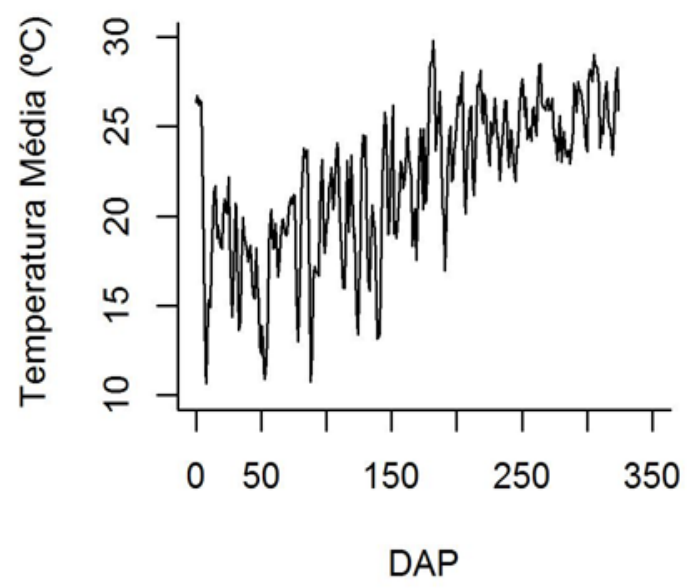

Experimento_04

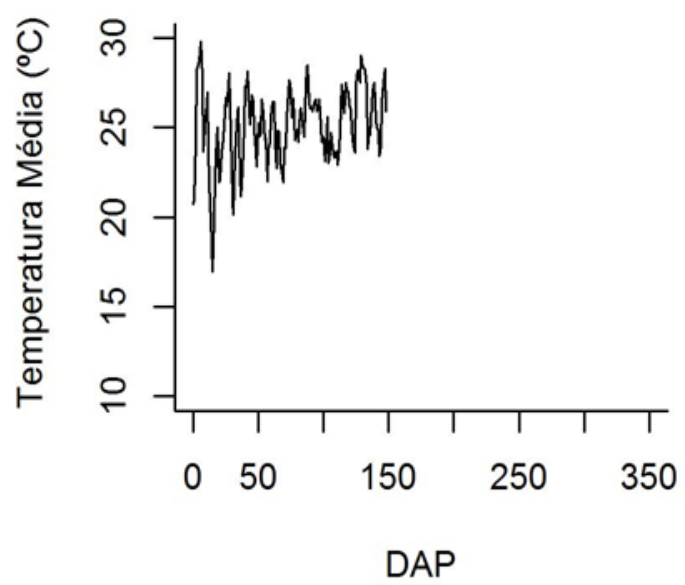

Figura 2. Temperatura média diária nos quatro experimentos realizados nos dois ambientes de produção, entre outubro de 2014 e março de 2017. 


\section{Experimento_01}

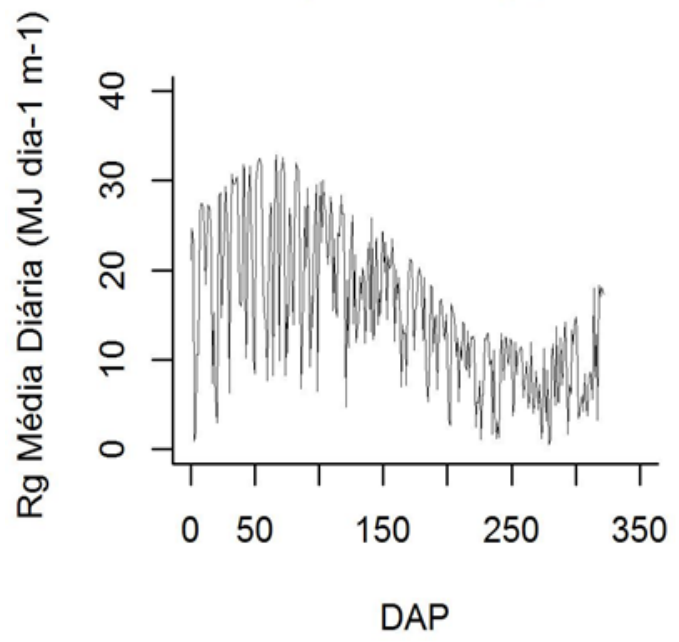

Experimento_03

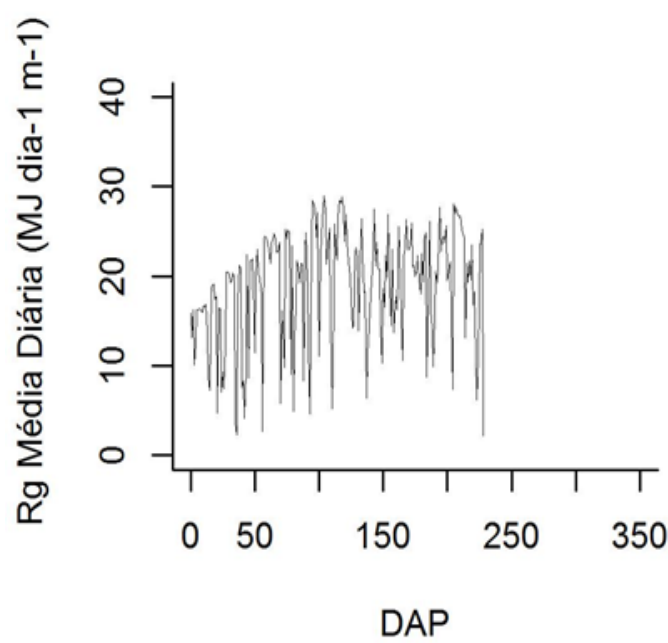

Experimento_02

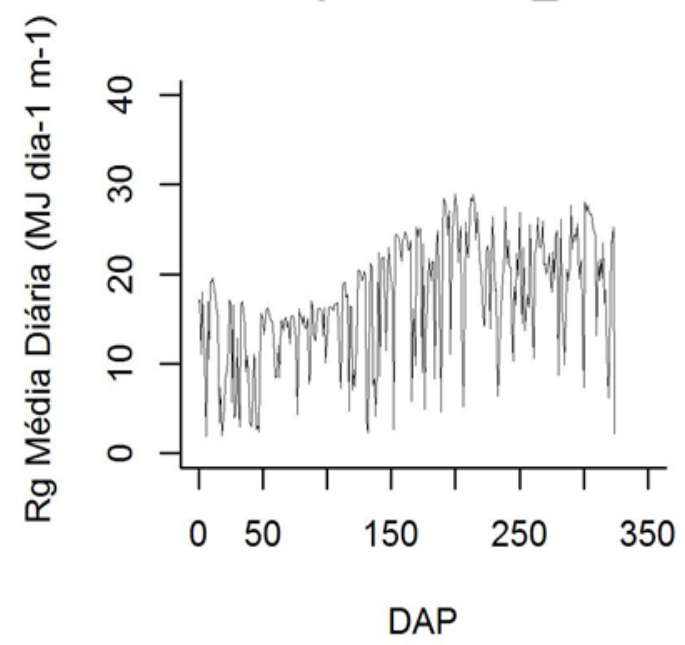

Experimento_04

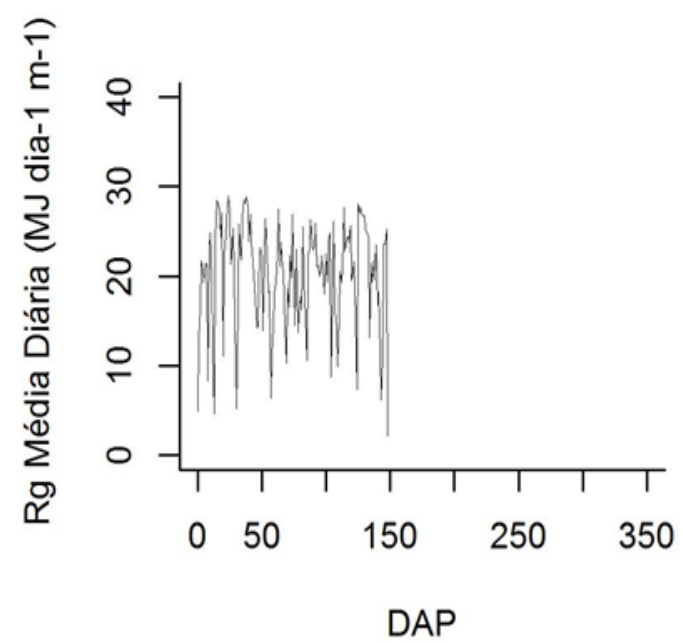

Figura 3. Radiação solar global (Rg) média diária nos quatro experimentos realizado nos dois ambientes de produção, entre outubro de 2014 e março de 2017.

Temperaturas limiares inferiores que causam paralisação no crescimento da cultura, são divergentes entre alguns autores, variando entre $15^{\circ} \mathrm{C}$ a $21^{\circ} \mathrm{C}$ (DILLEWIJN, 1952; BARBIERI; VILLA NOVA, 1977; BACCHI; SOUZA, 1978; DOORENBOS; KASSAM, 1979; MAGALHÃES, 1987; SCARPARI, 2002). Assim, temperaturas médias diárias acima de $21^{\circ} \mathrm{C}$ é o comumente utilizado para limiar o bom crescimento e desenvolvimento da cultura da cana-de-açúcar. Observa-se que até cerca de 150 DAP a temperatura média diária no experimento 2 foi abaixo da margem supracitada (Figura 2). Este fato pode ser um dos responsáveis pelo número baixo de perfilhos apresentado neste experimento em relação aos demais.

No experimento 1, nota-se uma diminuição na temperatura média diária na segunda metade do ciclo, o que é propício para a maturação da cultura. O contrário ocorreu no experimento 2 , onde a temperatura média diária na segunda metade do ciclo manteve-se elevada. A baixa redução de perfilhos apresentado no experimento $2 \mathrm{em}$ relação aos demais pode ser devido ao comportamento da temperatura, uma vez que quando a mesma se eleva, pode aumentar o perfilhamento (DILLEWIJN, 1952). Neste caso, a contribuição da temperatura em elevação não foi no aumento de perfilhos, mas sim na diminuição da taxa de decaimento dos mesmos.

Em alusão a radiação solar, Marafon (2012) afirma que para o bom crescimento e desenvolvimento da cultura são necessários dias com radiação solar global média acima de $18 \mathrm{MJ} \mathrm{m}^{-2}$ dia $^{-1}$. Observa-se na Figura 3 que a radiação solar global possui uma alta variação diária. Dias com precipitação, dias nublados e dias com elevado número de nuvens diminui considerávelmente a radiação que chega ao dossel da planta. Os experimentos 2 e 3 , ou seja, plantados em abril e julho, foram prejudicados devido a baixa incidência 
de radiação solar nos meses iniciais do cultivo, causado pela inclinação de incidência solar das estações de outono e inverno.

Considerando como limiares inferiores a temperatura de $21^{\circ} \mathrm{C}$ e radiação solar global de $18 \mathrm{MJ} \mathrm{dia}^{-1} \mathrm{~m}^{-2}$ para que a cultura de cana-de-açúcar tenha condições ótimas para o desenvolvimento e crescimento, observou-se que o experimento 4, que atingiu o ponto máximo de perfilhamento mais cedo que os demais, precisou de 45 dias de temperatura acima dos $21^{\circ} \mathrm{C}$ e 40 dias de radiação acima dos $18 \mathrm{MJ}$ $\mathrm{dia}^{-1} \mathrm{~m}^{-2}$ (Figura 4 e 5). Em contra partida o experimento 2 , que levou mais DAP para atingir o número máximo de perfilhos, necessitou de 62 e 51 dias de temperatura e radiação propícios, respectivamente. No entanto, o experimento 1 , plantado em outubro como o experimento 4, necessitou de
88 e 80 dias de temperatura e radiação propícios, respectivamente.

Pode-se observar na Figura 4 que a ordem de dias para atingir o mais elevado número de perfilhos é proporcional a temperatura, isto é, quanto mais elevado a temperatura até o ápice de perfilhos, mais rápido ocorre o mesmo. Isto indica que temperatura ambiente tem correlação positiva com perfilhamento.

O mesmo fato acontece com a radiação solar global média (Figura 5). Nota-se que os ambientes 1 e 4 que foram os que apresentaram os mais elevados números de perfilhos são também os experimentos de maior incidência de radiação na fase inicial da cultura.

Vale ressaltar que o experimento 2, apesar de mostrar os menores valores de $\mathrm{Rg}$ e temperatura, foi o que mos-

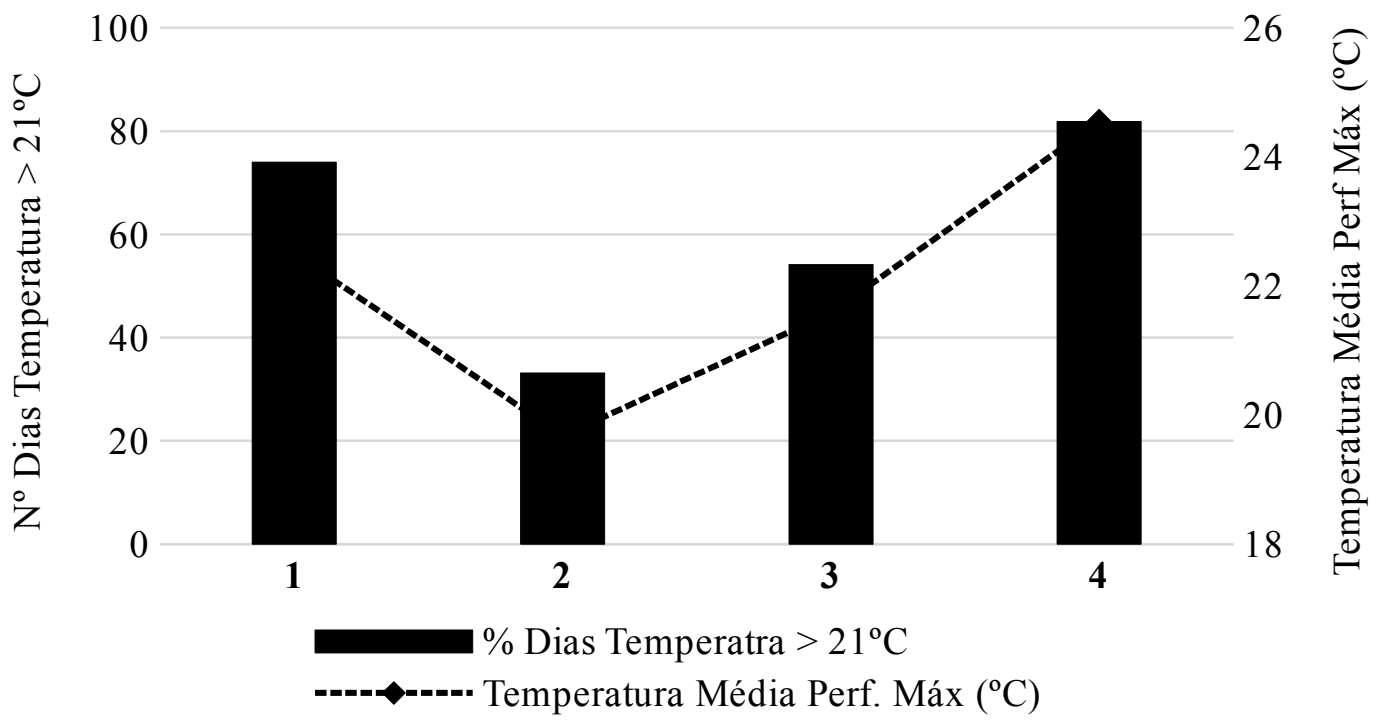

Figura 4. Porcentagem de dias com temperatura ambiente acima de $21^{\circ} \mathrm{C}$ e temperatura média durante o período até atingir o ponto máximo de perfilhamento nos quatro experimentos realizados nos dois ambientes de produção, entre outubro de 2014 e março de 2017.

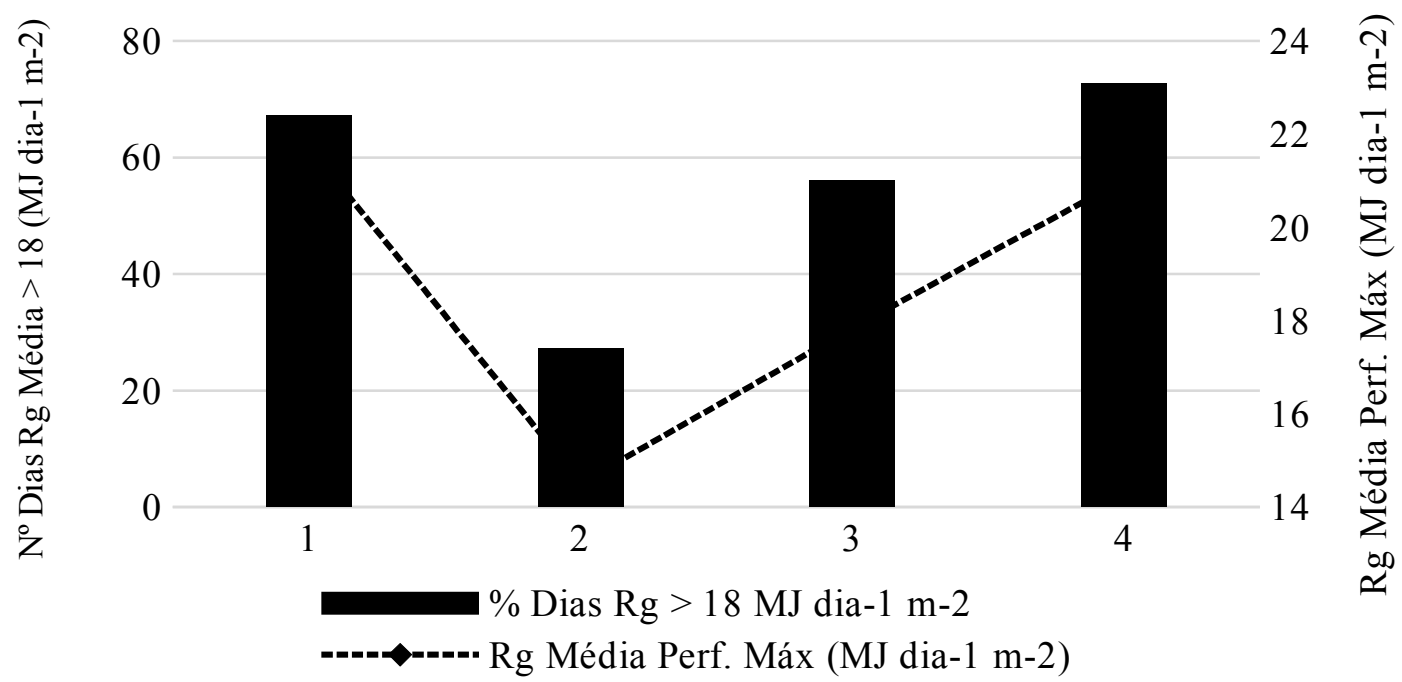

Figura 5. Porcentagem de dias com radiação solar global (Rg) média acima de $18 \mathrm{MJ}$ dia-1 $\mathrm{m}^{-2}$ e radiação solar global (Rg) média durante o período até atingir o ponto máximo de perfilhamento nos quatro experimentos realizados nos dois ambientes de produção, entre outubro de 2014 e março de 2017. 
trou menor diminuição ao longo do ciclo e que, a redução de perfilhos acentuada do experimento 1 é levemente intensificada em relação aos outros experimentos, devido o expaçamento entrelinhas ter sido $10 \mathrm{~cm}$ menor que os demais.

\section{Conclusões}

Os experimentos 1, 2, 3 e 4 apresentaram, respectivamente, 119, 187, 109 e 55 dias após plantio para atingir o máximo número de perfilhos por metro linear. Os ambientes dos experimentos 1 e 4 atingiram os maiores valores de máximo perfilhos por metro linear, maior incidência de radiação solar global e temperaturas mais elevadas até atingirem o máximo perfilhos. Os mesmos ambientes aprensentaram radiação solar global média de 21,7 e 21 MJ dia ${ }^{-1} \mathrm{~m}^{-2}$, e temperatura diária média de 22,5 e 24,5 ${ }^{\circ} \mathrm{C}$, respectivamente. Os plantios realizados nos meses de outubro atingiram os maiores valores de número máximo de perfilhos.

\section{Agradecimentos}

A Coordenação de Aperfeiçoamento de Pessoal de Nível Superior pela concessão da bolsa de estudo. Ao Programa de Pós-Graduação em Produção Vegetal da Universidade Federal do Paraná. A Embrapa Clima Temperado e ao Programa de Melhoramento Genético da Cana-de-áçúcar e a Rede Interuniversitária para o desenvolvimento do setor sucroenergético .

\section{Referências}

ALMEIDA, A. C. DOS S.; SOUZA, J. L.; TEODORO, I.; BARBOSA, G. V. S.; MOURA FILHO, G.; FERREIRA JÚNIOR, R. A. Desenvolvimento vegetativo e produção de variedades de cana-de-açúcar em relação à disponibilidade hídrica e unidades térmicas. Ciência e Agrotecnologia, v.32, p.1441-1448, 2008

BACHHI, O. O. S.; SOUZA, J. A. G. C. Minimum threshold temperature for sugar cane growth. In: CONGRESS OF THE INTERNATIONAL SOCIETY OF SUGARCANE TECHNOLOGISTS, 1. 1978. London. Anais... London: ISSSCT, 1978. v. 2, p 1733-1741.
BARBIERI, V.; VILLA NOVA, N. A. Climatologia e a cana-de-açúcar. Araras: PLANALSUCAR, Coordenaria Regional Sul, 1977. $22 \mathrm{p}$

CONAB. Companhia Nacional do Abastecimento. Levantamento da produção de cana-de-açúcar. 2017. Disponível em: http://www.conab. gov.br/OlalaCMS/uploads/arquivos/17_04_19_11_27_36_boletim_cana_ portugues_-_4o_lev_-_16-17.pdf. Acesso em: 20 abr. 2017.

DILLEWIJN, C. van. Botany of sugarcane: The Chronica Botanica. New York: Stechert-Hafner,1952.371 p.

DOORENBOS, J.; KASSAM, A. H. Yield response to water. Rome: FAO, 1979. 179 p. (FAO. Irrigation and Drainage Paper, 33).

EMBRAPA, E. B. D. P. A. Sistema Brasileiro de Classificação de Solos. Brasília: Embrapa Produções de Informações; Rio de Janeiro: Embrapa Solos, 306p., 2006.

MAGALHÃES, A. C. N. Ecofisiologia da cana-de-açúcar: aspectos do metabolismo do carbono na planta. In: CASTRO, P. R. C.; FERREIRA, S. O.; TSUIOSHI, Y. Ecofisiologia da produção agrícola. Piracicaba: POTAFOS, 1987. P. 115-118.

MARAFON, A. C. Análise quantitativa de crescimento em canade-açúcar : uma introdução ao procedimento prático. - Aracaju: Embrapa Tabuleiros Costeiros, 2012. 29 p. (Documentos / Embrapa Tabuleiros Costeiros, ISSN 1678-1953; 168). 1ª Edição. Disponível em: http://www.cpatc.embrapa.br/publicacoes_2012/doc_168.pdf. Acesso em: 19 set. 2014.

OLIVEIRA, R. A.; DAROS, E; ZAMBON, J. L. C.; WEBER, H.; IDO, O. I.; ZUFFELLATO-RIBAS, K. C.; KOEHLER, H. S.; SILVA, D. K. T. Crescimento e desenvolvimento de três cultivares de cana-de-açúcar, em cana-planta, no Estado do Paraná. Revista Scientia Agrária. Curitiba, v. 5, n. 1-2, p. 87-94, 2004.

SCARPARI, M. S. Modelos para a previsão da produtividade da canade-açúcar (Saccharum spp) através de parâmetros climáticos. 2002. 94 p. Dissertação (Mestrado Fititecnia) - Escola Superior de Agricultura "Luiz de Queiroz", Universidade de São Paulo, Piracicaba.

SEPLAG-EMATER Atlas socioeconômico Rio Grande do Sul. Disponível em: http://www.scp.rs.gov.br/atlas. Acesso em: 20 set. 2015.

SUGUITANI, C. Entendendo o crescimento e produção da cana-deaçúcar: avaliação do modelo Mosicas. 2006. 60 p. Tese (Doutorado em Agronomia) - Escola Superior de Agricultura "Luiz de Queiroz", Universidade de São Paulo, Piracicaba.

SUGUITANI, C.; MATSUOKA, S. Efeitos do fósforo nas características industriais agrícola em cana-de-açúcar (cana planta) cultivada em duas regiões do estado de São Paulo. In: CONGRESSO BRASILEIRO DE CINECIA DO SOLO, 28., 2001, Londrina. Ciência do solo: fator de produtividade competitiva com sustentabilidade; resumos... Londrina: SBCS, 2011. P. 119.

VERISSIMO, M. A. A. Desempenho agronômico de genótipos de canade-açúcar no estado do Rio Grande do Sul. Dissertação (Mestrado) Programa de Pós-Graduação em Sistemas de Produção Agrícola Familiar. Universidade Federal de Pelotas. 2012. 81p.

REFERENCIAÇÃO ARAÚJO, R. M.; OLIVEIRA, R. A. de; CUADRA, S. V.; ALMEIRA, I. R. de; WEBER, H. Condições agrometeorológicas para perfilhamento máximo da cultura de cana-de-açúcar em dois ambientes distintos de produção. Agrometeoros, Passo Fundo, v.25, n.1, p.257-264, 2017.

Declaração: os trabalhos estão sendo publicados nesse número de AGROMETEOROS (v.25, n.1, ago 2017) conforme foram aceitos pelo XX Congresso Brasileiro de Agrometeorologia, realizado de 14 a 18 de agosto de 2017, em Juazeiro, BA e Petrolina, PE, sem revisão editorial adicional da revista. 


\title{
Agrometeorological conditions from maximum perfilmation of sugar cane culture in two differents environments of production
}

\author{
Renã Moreira Araújo ${ }^{1}$, Ricardo Augusto de Oliveira ${ }^{2(*)}$, Santiago Vianna Cuadra ${ }^{3}$, Ivan Rodrigues de Almeida ${ }^{4}$, Heroldo Weber ${ }^{5}$ \\ ${ }^{1}$ Doutorando do Programa de Produção Vegetal, Universidade Federal do Paraná, Curitiba, Paraná, rena543@gmail.com \\ ${ }^{2}$ Professor Adjunto do Programa de Produção Vegetal, Universidade Federal do Paraná, Curitiba, Paraná, rico@ufpr.br \\ ${ }^{3}$ Pesquisador, Embrapa Clima Temperado, Pelotas, Rio Grande do Sul, santiago.cuadra@embrapa.br \\ ${ }^{4}$ Pesquisador, Embrapa Clima Temperado, Pelotas, Rio Grande do Sul, ivan.almeida@embrapa.br \\ ${ }^{5}$ Engenheiro Agronômo, Universidade Federal do Paraná, Curitiba, Paraná, heroldo@ufpr.br \\ (*)Corresponding author
}

\section{ARTICLE INFO}

\section{Article history:}

Received 16 June 2017

Accepted 10 August 2017

\section{Index terms:}

Saccharum officinarum $L$.

RB867515

temperature

radiation solar

\section{ABSTRACT}

Studies that understand the behavior of sugarcane genotypes in different production environments are of high importance, since they are useful information in several areas of study. The objective of this work was to analyze the temperature and solar radiation conditions that the commercial variety RB867515 needed to reach the maximum number of tillers in two distinct production environments, located to the south of the State of Rio Grande do Sul and in the northwest region of the State of Paraná. Were used tiller data from four experiments conducted between October 2014 and April 2017. Were used $1.4 \mathrm{~m}$ spacing in experiment 1 (RS) while in the other experiments (2,3 and 4-PR) were $1.5 \mathrm{~m}$. All the plantations were in cane toes, with $10 \mathrm{~cm}$ of depth and average distribution of 18 gems by linear meter. In the tiller count, the completely causal design was used, with four replications at each sampling, along the days after planting (DAP). The meteorological data used were mean temperature and global solar radiation. The environments presented different times to reach the maximum number of tillers per linear meter; The environments with the highest incidence of global solar radiation and higher temperatures in the initial phase of the cycle reached higher values of maximum tillers; October plantings reached higher values of maximum number of tillers; Maximum number of tillers did not necessarily indicate a high number of industrializable stalks.

(c) 2017 SBAgro. All rights reserved.

CITATION

ARAÚJO, R. M.; OLIVEIRA, R. A. de; CUADRA, S. V.; ALMEIRA, I. R. de; WEBER, H. Condições agrometeorológicas para perfilhamento máximo da cultura de cana-de-açúcar em dois ambientes distintos de produção. Agrometeoros, Passo Fundo, v.25, n.1, p.257-264, 2017.

Disclaimer: papers are published in this issue of AGROMETEOROS (v. 25, n.1, aug 2017) as accepted by the XX Congresso Brasileiro de Agrometeorologia, held August 14-18, 2017 in Juazeiro, Bahia and Petrolina, Pernambuco, Brazil, without further revision by editorial board. 